\title{
Ushering the Cactvs Toolkit into the Python Age (without breaking the legacy)
}

\author{
Wolf D Ihlenfeldt \\ From 9th German Conference on Chemoinformatics \\ Fulda, Germany. 10-12 November 2013
}

The Cactvs Chemoinformatics Toolkit is probably the most powerful general-purpose chemical information processing toolkit on the market. Since its inception about twenty years ago, its main language for rapid script development has been $\mathrm{Tcl}$ - at that time a language at the forefront of lazily-typed rapid prototyping and interface programming language design.

While Tcl is still actively maintained, and does provide features not matched by many of the nowadays more popular competitors - most notably impressive multithreading capabilities, which are fully accessible from within the toolkit - history has passed on. Tcl has undeniably fallen out of the public eye, and there is an understandable reluctance by users to learn new languages which are effectively only used by one of their tools.

This problem has finally been addressed. The Cactvs toolkit is now available with Python as a second alternative (or parallel) interface language. The new interface closely follows the established Tcl command patterns to support easy migration by experienced users, while still providing true "pythonesque" constructs. Since significant functionality of the toolkit is implemented as external Tcl script function snippets, and future enhancements will probably preferably be coded in Python without providing also a Tcl port, providing automatic and fully transparent access to language-mismatched components has been an important and rather peculiar design goal.

Examples of the new toolkit scripting capabilities shall be presented, as well as a documentation of the challenges involved in the design of a parallel multi-language interface to a large software system.

\section{Acknowledgements \\ We gratefully acknowledge support by Vertex Pharmaceuticals, Inc. for this project.}

\section{Correspondence: wdi@xemistry.com \\ Xemistry GmbH, Königstein, D-61462, Germany

Published: 11 March 2014

doi:10.1186/1758-2946-6-S1-P34

Cite this article as: Ihlenfeldt: Ushering the Cactvs Toolkit into the Python Age (without breaking the legacy). Journal of Cheminformatics 2014 6(Suppl 1):P34.

\section{Publish with ChemistryCentral and every scientist can read your work free of charge \\ "Open access provides opportunities to our colleagues in other parts of the globe, by allowing anyone to view the content free of charge." \\ W. Jeffery Hurst, The Hershey Company. \\ - available free of charge to the entire scientific community \\ - peer reviewed and published immediately upon acceptance \\ - cited in PubMed and archived on PubMed Central \\ - yours - you keep the copyright \\ Submit your manuscript here: \\ http://www.chemistrycentral.com/manuscript/

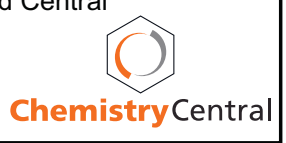

